\title{
Penetration in vitro of bovine oocytes during maturation by frozen-thawed spermatozoa
}

\author{
K. Niwa, C.-K. Park and K. Okuda \\ Division of Animal Science, Faculty of Agriculture, Okayama University, Okayama 700, \\ Japan
}

\begin{abstract}
Summary. Bovine immature oocytes cultured for various times in TC-199 medium were inseminated with frozen-thawed spermatozoa in Medium BO with caffeine ( $5 \mathrm{mM})$ and heparin $(10 \mu \mathrm{g} / \mathrm{ml})$. Very high penetration rates $(95-100 \%)$ were obtained in all oocytes which had been cultured for $0-20 \mathrm{~h}$. When oocytes cultured for 0 and $4 \mathrm{~h}$ were inseminated, $100 \%$ of them were penetrated and had a decondensing sperm head and most of the oocytes remained at the stage of condensed germinal vesicle (GV) to telophase-I $20-22 \mathrm{~h}$ after insemination. The formation of male and female pronuclei was first observed in oocytes inseminated $8 \mathrm{~h}$ after culture. The proportions of polyspermy and average number of spermatozoa in penetrated oocytes gradually decreased as oocyte maturation proceeded. Penetration of at least one spermatozoon with a decondensing head into oocytes at the GV stage (without culture) was almost completed up to $8 \mathrm{~h}$ after insemination and at that time most of the penetrated oocytes were still at the stage of $\mathrm{GV}$ or condensed GV. These results indicate that maturation of bovine oocytes is not required for sperm penetration into the vitellus or for sperm nuclear decondensation under the in-vitro conditions used.
\end{abstract}

Keywords: in-vitro fertilization; immature oocytes; maturation; bovine; sperm nuclear decondensation

\section{Introduction}

It has been reported for the mouse (Iwamatsu \& Chang, 1972), hamster (Barros \& Munoz, 1974), rabbit (Overstreet \& Bedford, 1974), rat (Niwa \& Chang, 1975) and human (Overstreet \& Hembree, 1976; Overstreet et al., 1980) that the zonae pellucidae of immature oocytes at the germinal vesicle stage are penetrable by spermatozoa. However, decondensing sperm heads are seldom observed within the cytoplasm under a phase-contrast microscope. From this it has been concluded that spermatozoa in the perivitelline space do not fuse with the plasma membrane of immature oocytes and are not incorporated into the vitellus. Electron microscopic observations, however, have revealed that, although hamster (Usui \& Yanagimachi, 1976; Moore \& Bedford, 1978 ) and rabbit (Berrios \& Bedford, 1979) spermatozoa are able to fuse with the plasma membrane of immature oocytes, decondensation of the sperm nucleus does not occur. The nature of factor(s) for preventing sperm nuclear dispersion in immature oocytes is unknown and may not be necessarily constant among different mammals. In the dog, unlike all other mammalian species so far investigated, spermatozoa can penetrate the vitellus and sperm nuclear decondensation follows in vitro (Mahi \& Yanagimachi, 1976). This seems to be reasonable, because oocytes are ovulated at the germinal vesicle stage in the dog (Van der Stricht, 1923).

The present light microscopic study was designed to determine the possibility of penetration in vitro of bovine follicular oocytes at various stages during maturation. It was also investigated whether sperm heads can be decondensed in the cytoplasm of the oocytes at the germinal vesicle stage. 


\section{Materials and Methods}

The basic medium used for the treatment of spermatozoa and the fertilization of oocytes was essentially the same as that used by Brackett \& Oliphant (1975) for the fertilization of rabbit eggs in vitro. The medium, designated Medium BO, comprised 112.0 mM-NaCl, $4.02 \mathrm{mM}-\mathrm{KCl}, 2.25 \mathrm{~mm}-\mathrm{CaCl}_{2}, 0.83 \mathrm{~mm}-\mathrm{NaH}_{2} \mathrm{PO}_{4}, 0.52 \mathrm{~mm}-\mathrm{MgCl}_{2}$, $37.0 \mathrm{~mm}-\mathrm{NaHCO}_{3}, 13.9 \mathrm{~mm}$-glucose, $1.25 \mathrm{~mm}$-sodium pyruvate and $31 \mu \mathrm{g}$ potassium penicillin $\mathrm{G} / \mathrm{ml}$.

Ovaries were removed from cows at a local slaughterhouse and returned to the laboratory in saline at $30-32^{\circ} \mathrm{C}$ within $1.5 \mathrm{~h}$. Oocytes were aspirated through a 24 -gauge needle into a disposable $1-\mathrm{ml}$ syringe from follicles of 3-5 mm in diameter. The collected oocytes were washed four times with TC-199 medium (with Earle's salts) buffered with $25 \mathrm{~mm}$ - $N$-2-hydroxyethylpiperazine $N$-2-ethane sulphonic acid (Hepes) and supplemented with $10 \%(\mathrm{v} / \mathrm{v})$ heated fetal calf serum, $100 \mu \mathrm{g}$ penicillin $\mathrm{G} / \mathrm{ml}$ and $100 \mu \mathrm{g}$ streptomycin $/ \mathrm{ml}$. Five to seven oocytes with cumulus cells were carefully transferred into a polystyrene culture dish $(35 \times 10 \mathrm{~mm})$ containing $100 \mu$ l of the same medium covered with warm paraffin oil and cultured at $39^{\circ} \mathrm{C}$ in an atmosphere of $5 \% \mathrm{CO}_{2}$ in air. After culture for $0,4,8,12,16$ or $20 \mathrm{~h}$, oocytes were washed twice and placed into $50 \mu$ l Medium BO supplemented with $20 \mathrm{mg}$ bovine serum albumin/ml (BSA; crystallized and lyophilized, essentially globulin free, No. A-7638; Sigma Chemical Co., St Louis, MO, USA) and $20 \mu \mathrm{g}$ pig intestinal mucosal heparin/ml (176 USP units $/ \mathrm{ml}$; Sigma Chemical $\mathrm{Co}$.), which had been previously covered with warm paraffin oil in a culture dish. The dishes were kept in a $\mathrm{CO}_{2}$ incubator $\left(5 \% \mathrm{CO}_{2}\right.$ in air at $\left.39^{\circ} \mathrm{C}\right)$ for about 30 min until spermatozoa were added for fertilization.

Spermatozoa were treated using the procedures reported previously (Niwa \& Ohgoda, 1988; Park et al., 1989). Briefly, two $0.5-\mathrm{ml}$ straws of frozen semen obtained from a Holstein bull (P-123) were thawed in a water bath at $35-37^{\circ} \mathrm{C}$. Spermatozoa were washed twice in Medium BO supplemented with $10 \mathrm{~mm}$-caffeine-sodium benzoate (Sigma Chemical Co.) by centrifugation at $833 \mathrm{~g}$ for a period of $10 \mathrm{~min}$ each. A $50-\mu \mathrm{l} \mathrm{sample}$ of final sperm suspension $\left(5-10 \times 10^{6}\right.$ spermatozoa/ml) was introduced into $50 \mu \mathrm{l}$ of the medium that included the oocytes. The mixture gave final concentrations of $2.5-5 \times 10^{6}$ spermatozoa $/ \mathrm{ml}, 10 \mathrm{mg} \mathrm{BSA} / \mathrm{ml}, 10 \mu \mathrm{g}$ heparin $/ \mathrm{ml}$ and $5 \mathrm{~mm}$-caffeine.

At $20-22 \mathrm{~h}$ after insemination, oocytes were mounted, fixed for $48-72 \mathrm{~h}$ at room temperature in $25 \%(\mathrm{v} / \mathrm{v})$ acetic alcohol, stained with $1 \%(\mathrm{w} / \mathrm{v})$ orcein in $45 \%(\mathrm{v} / \mathrm{v})$ acetic acid, and examined for evidence of sperm penetration as described previously (Ohgoda et al., 1988). In another experiment, oocytes at the germinal vesicle stage without culture for maturation were incubated with or without spermatozoa in $100 \mu \mathrm{l}$ Medium BO containing $10 \mathrm{mg} \mathrm{BSA} / \mathrm{ml}$, $10 \mu \mathrm{g}$ heparin/ml and $5 \mathrm{~mm}$-caffeine. Oocytes were examined at various times after incubation for evidence of sperm penetration and oocyte nuclear maturation. Oocytes were considered as penetrated when they had decondensed sperm heads or pronuclei and their corresponding sperm tails in the cytoplasm.

\section{Results}

As shown in Table 1, very high penetration rates (95-100\%) were obtained equally in all oocytes which had been cultured for $0-20 \mathrm{~h}$ for maturation. All the oocytes inseminated 0 and $4 \mathrm{~h}$ after culture were penetrated and had a decondensing sperm head and most of the penetrated oocytes were at the stage of condensed germinal vesicle (GV; Fig. la, b) to telophase-I. Oocytes penetrated with male and female pronuclei were first observed when they were inseminated $8 \mathrm{~h}$ after culture, and their proportions increased as time of insemination was delayed. Extremely high proportions of polyspermy were observed, especially in oocytes inseminated at early stages of maturation, and the proportions decreased as oocyte maturation proceeded. With increased oocyte maturation, there was also a rapid decline in the average number of spermatozoa in penetrated oocytes.

When oocytes at the GV stage were inseminated, a few (7\%) were already penetrated $4 \mathrm{~h}$ after insemination (Table 2; Fig. 1c-e). Sperm penetration of the oocytes was almost complete up to $8 \mathrm{~h}$ after insemination but the number of penetrating spermatozoa increased gradually with the lapse of time after insemination. Although oocytes penetrated and with decondensed sperm nuclei at the GV stage were observed until $20 \mathrm{~h}$ after insemination (Fig. 2), GV breakdown was first observed in penetrated oocytes $8 \mathrm{~h}$ after insemination. However, very few oocytes matured beyond prometaphase-I, even $20 \mathrm{~h}$ after insemination.

To examine whether the suppression of oocyte maturation was due to sperm penetration of the cytoplasm, oocytes at the GV stage were cultured without spermatozoa in Medium BO with caffeine and heparin, conditions which were the same as used for insemination. As shown in Table $3, \mathrm{GV}$ breakdown occurred as usual but maturation of most of the oocytes did not proceed beyond prometaphase-I. 


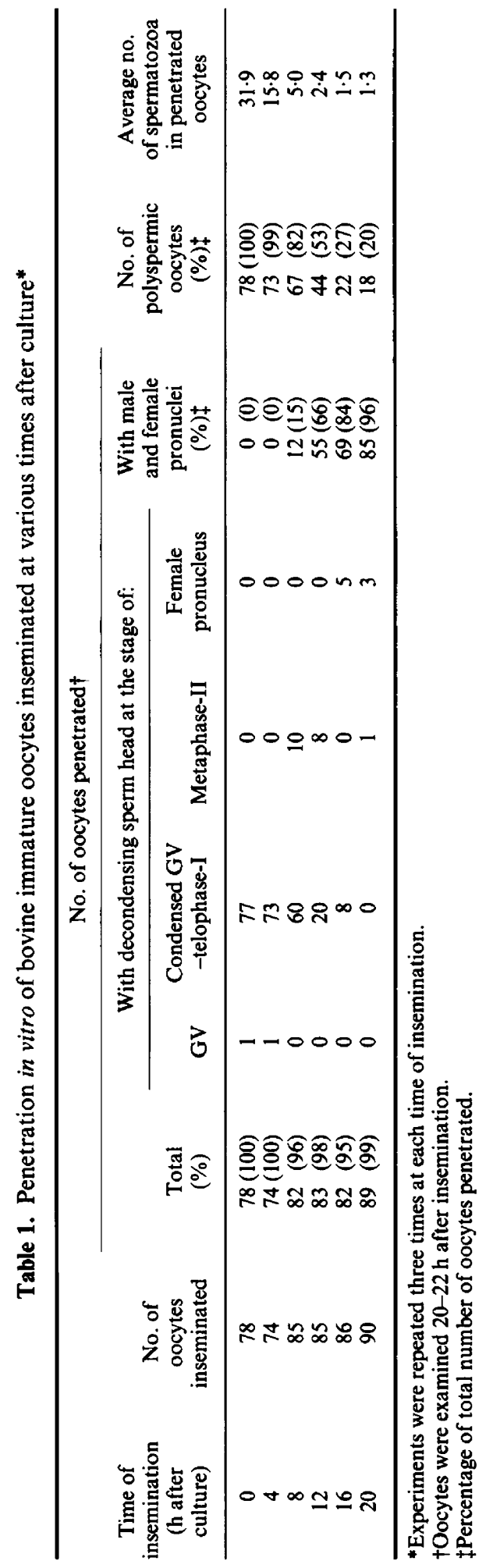



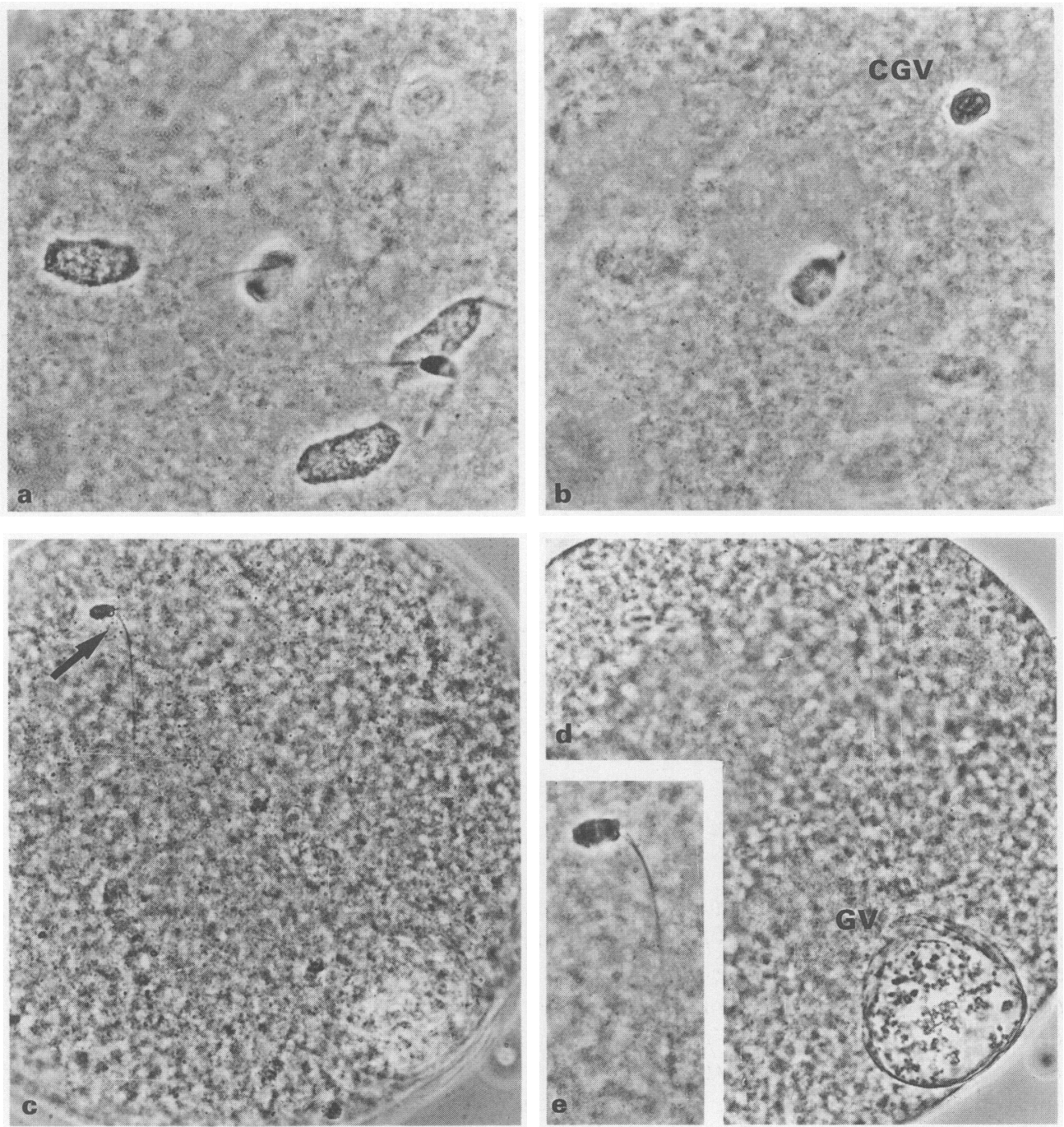

Fig. 1. Oocytes inseminated at the GV stage and fixed and stained at various times after insemination. (a, b) A polyspermic oocyte penetrated $22 \mathrm{~h}$ after insemination showing at least 4 decondensing sperm heads, some with penetrating sperm tails (a). (b) This oocyte has not completed maturation because it shows a condensed germinal vesicle $(\mathrm{CGV}) . \times 609$. (c-e) An oocyte penetrated $4 \mathrm{~h}$ after insemination. A penetrating spermatozoon (arrow) (c) and germinal vesicle $(\mathrm{GV})(\mathrm{d})$ are clearly visible. $\times 304$. Higher magnification of the penetrating spermatozoon indicated by an arrow in c shows the typical early stage of nuclear decondensation (e). $\times 609$.

\section{Discussion}

The results of the present study indicate that bovine ovarian oocytes at the GV stage and those undergoing maturation are equally penetrable by spermatozoa in vitro. The findings that oocytes at the GV stage are all penetrated with subsequent decondensation of sperm nuclei $20-22 \mathrm{~h}$ after insemination and that decondensation of sperm nuclei can be induced even before GV breakdown are profoundly interesting since, with only the exception of the dog observed in vitro (Mahi \& 
Table 2. Time of penetration in vitro of bovine oocytes inseminated at germinal vesicle stage*

\begin{tabular}{|c|c|c|c|c|c|c|c|c|}
\hline \multirow{2}{*}{$\begin{array}{c}\text { Time of } \\
\text { examination } \\
\text { ( } \mathrm{h} \text { after } \\
\text { insemination) }\end{array}$} & \multirow{2}{*}{$\begin{array}{c}\text { No. of } \\
\text { oocytes } \\
\text { examined }\end{array}$} & \multicolumn{5}{|c|}{ No. of oocytes penetrated $\dagger$ at the stage of: } & \multirow{2}{*}{$\begin{array}{c}\text { No. of } \\
\text { polyspermic } \\
\text { oocytes } \\
(\%) \ddagger\end{array}$} & \multirow{2}{*}{$\begin{array}{c}\text { Average no. } \\
\text { of spermatozoa } \\
\text { in penetrated } \\
\text { oocytes }\end{array}$} \\
\hline & & $\begin{array}{l}\text { Total } \\
(\%)\end{array}$ & GV & $\begin{array}{c}\text { Condensed } \\
\mathrm{GV}\end{array}$ & $\begin{array}{c}\text { Prometa- } \\
\text { phase-I }\end{array}$ & $\begin{array}{l}\text { Metaphase- } \\
\text { telophase-I }\end{array}$ & & \\
\hline 4 & 55 & $4 \quad(7)$ & 4 & 0 & 0 & 0 & $1(25)$ & 1.5 \\
\hline 8 & 59 & $56 \quad(95)$ & 36 & 17 & 3 & 0 & 41 (73) & $4 \cdot 1$ \\
\hline 12 & 54 & $52 \quad(96)$ & 18 & 14 & 20 & 0 & $50 \quad(96)$ & 9.5 \\
\hline 16 & 54 & $54(100)$ & 6 & 35 & 11 & 2 & $49(91)$ & 13.9 \\
\hline 20 & 50 & $50(100)$ & 7 & 23 & 18 & 2 & $50(100)$ & $26 \cdot 7$ \\
\hline
\end{tabular}

*Experiments were repeated twice at each time of examination. †All oocytes were penetrated with a decondensing sperm head. $\ddagger$ Percentage of total number of oocytes penetrated.

Table 3. Maturation of bovine oocytes cultured in Medium BO with caffeine and heparin*

\begin{tabular}{|c|c|c|c|c|c|c|}
\hline \multirow{2}{*}{$\begin{array}{l}\text { Time of } \\
\text { examination } \\
\text { (h after } \\
\text { culture) }\end{array}$} & \multirow[b]{2}{*}{$\begin{array}{l}\text { No. of } \\
\text { trials }\end{array}$} & \multirow{2}{*}{$\begin{array}{c}\text { No. of } \\
\text { oocytes } \\
\text { examined }\end{array}$} & \multicolumn{4}{|c|}{ No. of oocytes at the stage of: } \\
\hline & & & GV & $\begin{array}{c}\text { Condensed } \\
\text { GV }\end{array}$ & $\begin{array}{l}\text { Prometa- } \\
\text { phase-I }\end{array}$ & $\begin{array}{l}\text { Metaphase- } \\
\text { telophase-I }\end{array}$ \\
\hline 4 & 2 & 57 & 57 & 0 & 0 & 0 \\
\hline 8 & 3 & 71 & 39 & 32 & 0 & 0 \\
\hline 12 & 2 & 59 & 23 & 36 & 0 & 0 \\
\hline 16 & 3 & 70 & 3 & 40 & 27 & 0 \\
\hline 20 & 3 & 63 & 0 & 29 & 22 & 12 \\
\hline
\end{tabular}

${ }^{*}$ For details, see text.

Yanagimachi, 1976), there are no reports to show the same phenomena in other mammalian species. Usui \& Yanagimachi (1976) speculated that sperm nuclear decondensing factor is synthesized in the egg cytoplasm, transported to and accumulated in the $\mathrm{GV}$, and then released into the egg cytoplasm at the time of GV breakdown. Although the chemical nature of the factor remains to be determined, the present study indicates that, in immature bovine oocytes, such a factor seems to be active even before the GV material is released into the cytoplasm. Since, in the present study, the medium used for fertilization included caffeine and heparin, it is possible that these chemicals participate in the activation of the factor. This should be clarified in further experiments, but it is very difficult to fertilize bovine oocytes in this system without these chemicals (Niwa et al., 1988).

In the present study, development of male pronuclei was possible only when oocytes were inseminated at and after $8 \mathrm{~h}$ of culture for maturation. GV breakdown of bovine oocytes in vivo occurs between 4 and $8 \mathrm{~h}$ after the LH peak (Kruip et al., 1983) and this time interval is almost similar to that for oocytes cultured in vitro (Sirard et al., 1989). Therefore, the male pronucleus growth factor (Thibault \& Gerard, 1973) or the sperm pronucleus development factor (Yanagimachi, 1981) may become only partly active just after GV breakdown. The activation of the factor seems to be intensified gradually as the oocytes develop from GV breakdown to metaphase II. A similar occurrence was observed in oocytes of the mouse (Iwamatsu \& Chang, 1972), rat (Niwa \& Chang, 1975) and hamster (Usui \& Yanagimachi, 1976). On the other hand, most of the oocytes inseminated without culture for maturation were at the stage beyond $\mathrm{GV}$ breakdown $20 \mathrm{~h}$ later (Table 2) but formation of the male pronucleus was not observed in any of the oocytes penetrated (Tables 1 and 2). This may be due to limitation of the amount of materials supporting sperm pronuclear development present in the cytoplasm since so many spermatozoa were able to penetrate oocytes at the GV stage in the present study. In hamsters, when more than 9 spermatozoa enter one egg, none of the sperm heads develop into pronuclei (Hirao \& Yanagimachi, 1979). 

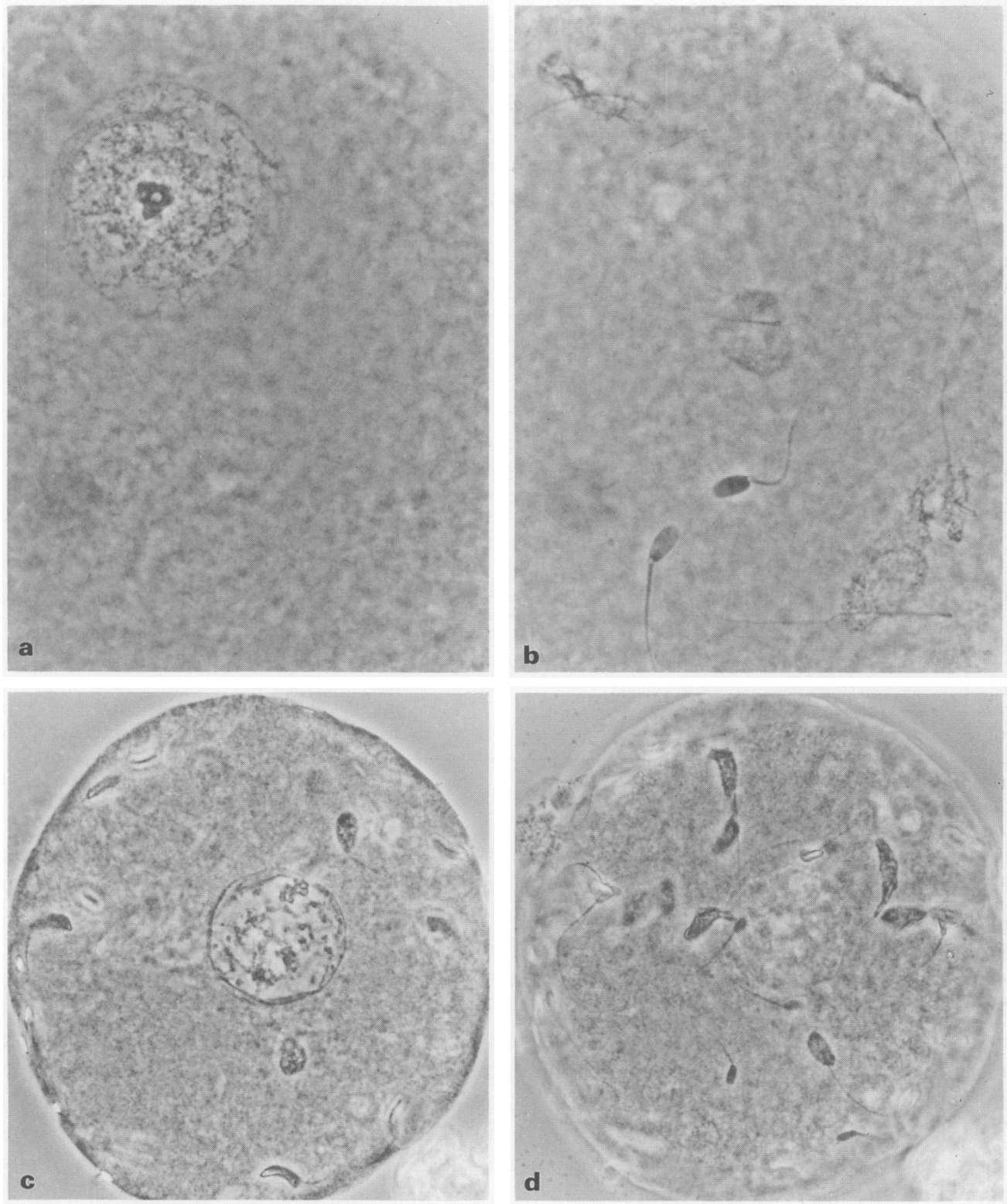

Fig. 2. Polyspermic oocytes penetrated at various times after insemination at the stage of the germinal vesicle. $(\mathbf{a}, \mathbf{b})$ An oocyte penetrated $12 \mathrm{~h}$ after insemination showing a germinal vesicle which is undergoing condensation (a) and at least 5 decondensing sperm heads with penetrating sperm tails (b). $\times 609$. (c, d) An oocyte penetrated $16 \mathrm{~h}$ after insemination. Many spermatozoa are penetrating with various stages of decondensation of sperm heads in different focal planes. This oocyte still has an intact germinal vesicle (c). $\times 304$.

We have reported for cattle that non-preincubated spermatozoa start to penetrate matured oocytes with cumulus and corona cells $3 \mathrm{~h}$ after insemination in vitro (Park et al., 1989). Since, in the present study, some of the oocytes at the GV stage were already penetrated $4 \mathrm{~h}$ after insemination, there seems to be little difference in the time of sperm penetration of mature and immature oocytes. However, the number of spermatozoa penetrating oocytes at the GV stage increased with 
time after insemination (Table 2). Since Fulka, Jr et al. (1982) have reported that, when zona-free bovine oocytes matured in culture are inseminated in vitro, only about $50 \%$ of penetrated oocytes are polyspermic, a block to polyspermy at the level of the plasma membrane seems to be strong in bovine oocytes. Therefore, in immature bovine oocytes, there seems to be no block to polyspermy at the level either of the zona pellucida or the plasma membrane. It is known in some species that the contents ejected from the cortical granules into the perivitelline space during fertilization alter the characteristics of the zona pellucida, and thus penetration of excess spermatozoa is prevented (for references, see Wolf, 1981). Ultrastructural studies by Hyttel et al. (1988) have revealed that abnormal cortical granule exocytosis does occur during fertilization of in-vitro matured bovine oocytes and allows polyspermy. Although we did not examine in the present study whether exocytosis of the cortical granules does occur during fertilization of oocytes at the GV stage, it has been demonstrated that there is complete failure of cortical granule exocytosis in intact GV oocytes of the hamster (Moore \& Bedford, 1978) and rabbit (Berrios \& Bedford, 1979).

Apparently, Medium BO with caffeine and heparin is not suitable for maturation of bovine oocytes (Table 3). Therefore, if some other medium which maintains both oocyte maturation and sperm penetration is used, we may be able to observe in more detail the development of the sperm nucleus, after penetration of oocytes at the GV stage, and prior oocyte maturation.

This work was supported by a grant from the Ryobiteien Foundation, Okayama, Japan. We thank L. R. Abeydeera for assistance in the preparation of the manuscript.

\section{References}

Barros, C. \& Munoz, G. (1974) Sperm penetration in vitro of mouse oocytes at various times after maturation. J. Reprod. Fert. 31, 237-247.

Berrios, M. \& Bedford, J.M. (1979) Oocyte maturation: Aberrant post-fusion responses of the rabbit primary oocyte to penetrating spermatozoa. J. Cell Sci. 39, $1-12$.

Brackett, B.G. \& Oliphant, G. (1975) Capacitation of rabbit spermatozoa in vitro. Biol. Reprod. 12, 260-274.

Fulka, J., Jr, Pavlok, A. \& Fulka, J. (1982) In-vitro fertilization of zona-free bovine oocytes matured in culture. J. Reprod. Fert. 64, 495-499.

Hirao, Y. \& Yanagimachi, R. (1979) Development of pronuclei in polyspermic eggs of the golden hamster: is there any limit to the number of sperm heads that are capable of developing into pronuclei? Zool. Mag. (Tokyo) 88, 24-33.

Hyttel, P., Xu, K.P. \& Greve, T. (1988) Ultrastructural abnormalities of in vitro matured bovine oocytes. Anat. Embryol. 178, 47-52.

Iwamatsu, T. \& Chang, M.C. (1972) Sperm penetration in vitro of mouse oocytes at various times after maturation. J. Reprod. Fert. 31, 237-247.

Kruip, T.A.M., Cran, D.G., Van Beneden, T.H. \& Dielemann, S.J. (1983) Structural changes in bovine oocytes during final maturation in vivo. Gamete Res. $8,29-47$.

Mahi, C.A. \& Yanagimachi, R. (1976) Maturation and sperm penetration of canine ovarian oocytes in vitro. J. exp. Zool. 196, 189-196.

Moore, H.D.M. \& Bedford, J.M. (1978) Ultrastructure of the equitorial segment of hamster spermatozoa during penetration of oocytes. J. Ultrastruct. Res. 62 , $110-117$.

Niwa, K. \& Chang, M.C. (1975) Fertilization of rat eggs in vitro at various times before and after ovulation with special reference to fertilization of ovarian oocytes matured in vitro. J. Reprod. Fert. 43, 435-451.

Niwa, K. \& Ohgoda, O. (1988) Synergistic effect of caffeine and heparin on in-vitro fertilization of cattle oocytes matured in culture. Theriogenology 30, $733-741$.

Niwa, K., Ohgoda, O. \& Yuhara, M. (1988) Effect of caffeine in media for pretreatment of frozen-thawed sperm on in-vitro penetration of cattle oocytes. Proc. Ilth Int. Congr. Anim. Reprod. A.I., Dublin 3, abstr. No. 346 ( 3 pages).

Ohgoda, O., Niwa, K., Yuhara, M., Takahashi, S. \& Kanoya, K. (1988) Variations in penetration rates in vitro of bovine follicular oocytes do not reflect conception rates after artificial insemination using frozen semen from different bulls. Theriogenology 29, 1375-1381.

Overstreet, J.W. \& Bedford, J.M. (1974) Comparison of the penetrability of the egg vestments in follicular oocytes, unfertilized and fertilized ova of the rabbit. Devl Biol. 41, 185-192.

Overstreet, J.W. \& Hembree, W.C. (1976) Penetration of the zona pellucida of non-living human oocytes by human spermatozoa in vitro. Fert. Steril. 27, 815-831.

Overstreet, J.W., Yanagimachi, R., Katz, D.F., Hayashi, K. \& Hanson, F.W. (1980) Penetration of human spermatozoa into the human zona pellucida and the zona-free hamster egg: a study of fertile donors and infertile patients. Fert. Steril. 33, 534-542.

Park, C.-K., Ohgoda, O. \& Niwa, K. (1989) Penetration of bovine follicular oocytes by frozen-thawed spermatozoa in the presence of caffeine and heparin. J. Reprod. Fert. 86, 577-582.

Sirard, M.A., Florman, H.M., Leibfried-Rutledge, M.L., Barnes, F.L., Sims, M.L. \& First, N.L. (1989) Timing of nuclear progression and protein synthesis 
necessary for meiotic maturation of bovine oocytes. Biol. Reprod. 40, 1257-1263.

Thibault, C. \& Gerard, M. (1973) Cytoplasmic and nuclear maturation of rabbit oocytes in vitro. Annls Biol. anim. Biochim. Biophys. 13, 145-156.

Usui, N. \& Yanagimachi, R. (1976) Behavior of hamster sperm nuclei incorporated into eggs at various stages of maturation, fertilization and early development: the appearance and disappearance of factors involved in sperm chromatin decondensation in egg cytoplasm. J. Ultrastruct. Res. 57, 276-288.

Van der Stricht, O. (1923) Etude comparee des ovules des mammiferes aux differentes periodes de l'ovogenese, d'apres les travaux du Laboratoire d'Histologie et d'Embryologie de l'Universite de Gand. Archs Biol., Paris 33, 229-300.

Wolf, D.P. (1981) The mammalian egg's block to polyspermy. In Fertilization and Embryonic Development in Vitro, pp. 183-197. Eds L. Mastroianni, Jr \& J. D. Biggers. Plenum Press, New York.

Yanagimachi, R. (1981) Mechanisms of fertilization in mammals. In Fertilization and Embryonic Development in Vitro, pp. 81-182. Eds L. Mastroianni, Jr \& J. D. Biggers. Plenum Press, New York.

Received 9 June 1990 